\title{
Progressive Collapse Study of Seismically Designed Low Rise Reinforced Concrete Framed Structure
}

\author{
Tariq Ahmad Sheikh", ${ }^{1,}$ J. M. Banday ${ }^{1}$, Mohammad Ahmed Hussain ${ }^{2}$ \\ ${ }^{1}$ Department of Civil Engineering, National Institute of Technology Hazratbal, Srinagar, 190006, Jammu and Kashmir, India \\ ${ }^{2}$ Department of Civil Engineering, I.S.L Engineering College, Bandlaguda, Chandrayangutta, Hyderabad, 500005, Telangana, India
}

Received April 22, 2021; Revised June 22, 2021; Accepted July 19, 2021

\begin{abstract}
Cite This Paper in the following Citation Styles
(a): [1] Tariq Ahmad Sheikh, J. M. Banday, Mohammad Ahmed Hussain, "Progressive Collapse Study of Seismically Designed Low Rise Reinforced Concrete Framed Structure," Civil Engineering and Architecture, Vol. 9, No. 5, pp. 1327 - 1338, 2021. DOI: 10.13189/cea.2021.090506.
\end{abstract}

(b): Tariq Ahmad Sheikh, J. M. Banday, Mohammad Ahmed Hussain (2021). Progressive Collapse Study of Seismically Designed Low Rise Reinforced Concrete Framed Structure. Civil Engineering and Architecture, 9(5), 1327 - 1338. DOI: 10.13189/cea.2021.090506.

Copyright $\odot 2021$ by authors, all rights reserved. Authors agree that this article remains permanently open access under the terms of the Creative Commons Attribution License 4.0 International License

\begin{abstract}
In this study, linear and non-linear static analysis of low-rise models representing two-bay two-story and three-bay three-story reinforced concrete framed structures designed as per Indian standard codes (IS 450:2000 and IS 1893:2016) for the high seismic region using Envelope loading combination are assessed with and without the Guidelines of U.S. (GSA) General Services Administration. The purpose of this study is to describe the applicability of Finite Element software in assessing the behavior of seismically designed low rise structure before and after losing vertical structural element column with and without considering dynamic increase factor, and the results indicate demand resistance ratios acquired from elastic linear analysis and the hinge formation pattern obtained from non-linear elastic analysis are similar for Envelope loading combination and GSA loading combination, thus the dynamic increase factor of 2 recommended by the U.S. General Services Administration guidelines for static analysis can be underestimated for low-rise reinforced concrete framed models designed seismically as far as progressive collapse resistance is considered, since both types of loading combinations (in which one combination considers only normal design load path method while the other combination considers alternate load path methods) acquire same type of results, thus confirms seismically designed low rise models does possess inherent property towards progressive collapse resistance. This study provides a good example and summary for the
\end{abstract}

construction industry and can be used by design engineers while designing low-rise progressive collapse-resistant structures.

Keywords Progressive Collapse, Low Rise Structure, Linear Static Analysis, U.S. (GSA) General Services Administration Guidelines, Non-linear Static Analysis, Demand Capacity Ratios (DCR)

\section{Introduction}

Progressive Collapse is enlightened by several researchers, Starossek [5] recognized different types of collapse failures, namely pancake, zipper, domino, section, instability and mixed type collapses. Managing anomalous occurrences, managing local element behavior, and/or controlling global system behavior are three strategies to reduce the likelihood of gradual collapse. Normally, structural engineers find it difficult to control unusual phenomena. Engineers, on the other hand, can alter the behavior of local and global systems, Starossek and Haberland [6]. Starossek [16] discusses innovative progressive collapse mechanisms that can be used on tall structures. Nonstructural protective measures, particular local resistance, alternate pathways, isolation of collapsing parts, and prescriptive design rules are among these solutions. Current design strategies for progressive 
collapse resistance, according to Starossek [19], are insufficient. In another paper, using a simplified model of the Alfred P. Murrah Federal Build, Starossek and Wolff [23] provides a brief review of direct design techniques for progressive collapse.

Frame structures are seismically designed using SAP2000 Version 20 [26] as per IS 1893-2016 [31]. Linear static analysis is enacted separately for each case of column elimination. The vertical structural element is detached from the position under consideration in the linear static analysis, and the linear static analysis with Envelope Loading Combination and G.S.A Loading Combination has been carved out of the structure. From the elastic analysis results, ultimatum at key positions of the beam elements is acquired and from the fundamental original seismically built section of the structure, the resistance of the horizontal member is decided. A check for the demand capacity ratio in each horizontal element is carted out. If the demand capacity ratio valve of horizontal member surpasses the acceptance criteria, the given member is deemed as unfit. The demand resistance ratio obtained from linear elastic analysis assists to ascertain the capability of building structure for progressive collapse.

"The Demand Capacity Ratio (DCR), defined as the ratio of the member force to the member strength is computed and analysed according to the U.S. General Services Administration guidelines. Member strength is computed using the area of steel obtained in the design results of the SAP2000 Program as per IS 456-2000 code" [28]. The member force is directly drawn from obtained design forces valves of the SAP2000 Program [26].

Non-linear static progressive collapse analysis includes a step-by-step application of vertical loads until an extreme amplified load of 2(D.L +L. L) is reached while allowing structural members to undergo non-linear behavior, which can be described to as pushdown analysis by Jalilkhani, Maysam, Manafpour, Ali Reza, 2018 [4].

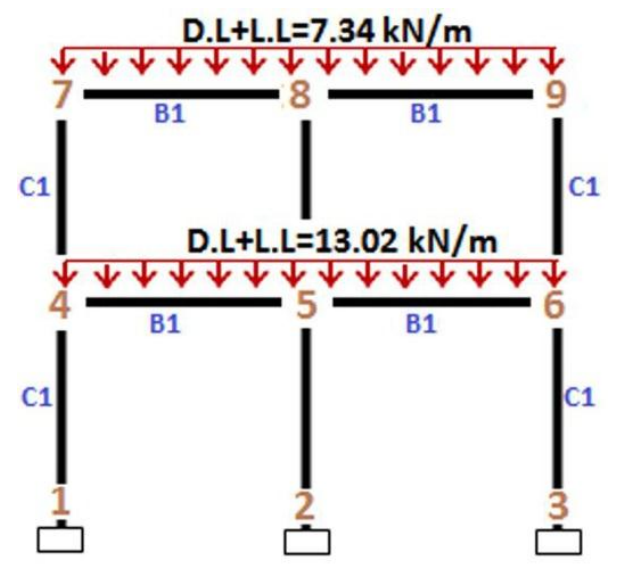

CASE A: 2 Bay 2Story
Non-linear static analysis is helpful in evaluating the resilient and collapse failure limits of the system, even though it cannot account for the dynamic effect due to the sudden missing of columns studied by E.Brunesi, F.Parisi, etal. [7]. "Experimental studies [14],[17],[18]; carried out on RC beam-column sub assemblages have shown the inherent ability to better resist progressive collapse of the specimens with seismic detailing". Numerical studies [2], [11], [13], [22]; demonstrated that seismic design improves the continuing collapse resistance of mid-rise (11...13 storey) RCC framed structures. Since structural efficiency under normal service loads is evaluated when analyzing for progressive collapse potential, it was shown that these structures will not collapse when columns are removed.

Therefore, the present study aims to assess the behavior of 2D low-rise $\mathrm{RC}$ framed structures to progressive collapse designed according to the provisions of the Indian standard codes (IS 456-2000 and IS 1893-2016) [28],[31] for Envelope loading Combination for high seismic regions where the peak ground acceleration is $0.36 \mathrm{~g}$, based on GSA criteria, the progressive collapse behavior is determined by conducting linear static analysis and non-linear static analysis procedure.

\section{Description of the Structure}

SAP2000. v.20 computer program [26] is used to craft a model of buildings structures and to scrutinize distribution and redistribution of loads before and after removing a column, Figure. 1 shows an elevation view of two-dimensional Reinforced concrete framed structures with 2-bay2story and 3-bay3story buildings. Figure.2a illustrates a typical plan view of these buildings with a square plan, and a span length of $3 \mathrm{~m}$ throughout respectively. These models were designed and checked as per Indian Standard codes [28], [31], [32]; respectively.

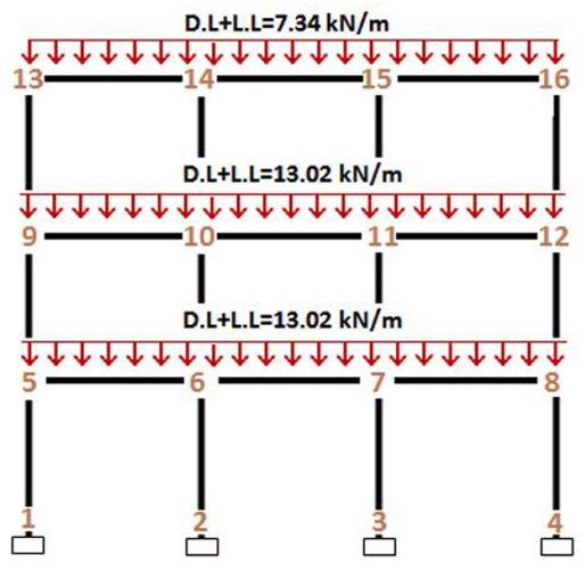

CASE C: 3 Bay 3Story

Figure 1. Elevation of two Cases used for the Study 


\subsection{Material and Sectional Property}

Building structures are analyzed and designed as per Indian standard codes IS 456:2000 [28] for envelope loading combination. The dimensions of columns and beams are similar for all stories and are $230 \mathrm{~mm} \times 230 \mathrm{~mm}$. Material properties used for the structures are M25 for beams and M30 for columns, unit weight of concrete as $25 \mathrm{~N} / \mathrm{mm} 3$. The elasticity modulus of steel and concrete are $200000 \mathrm{MPa}$ and $25000 \mathrm{MPa}$ (beams) to $27000 \mathrm{MPa}$ (columns) respectively.

\subsection{Loading Intensities Considered}

\subsubsection{Dead Load}

The dead load is computed from IS 875 (part1) [32]. Concrete is assumed to have a unit weight of $25 \mathrm{kN} / \mathrm{m} 3$. Self-weight of the building elements include:

Floor finish (except top floor) $=3 \mathrm{kN} / \mathrm{m}^{2}$, For Top floor $=1.5 \mathrm{kN} / \mathrm{m}^{2}$, Thickness of wall, Parapet wall and slab assumed as $110 \mathrm{~mm}, 90 \mathrm{~mm}$ and $120 \mathrm{~mm}$ respectively.

Hence total Dead Load on each frame and top floor frames are $10.77 \mathrm{kN} / \mathrm{m}$ and $5.085 \mathrm{kN} / \mathrm{m}$ respectively.

\subsubsection{Live Load}

IS 875(part2) [32] is used to estimate the live load. Same Live load on roof and floor $=3 \mathrm{kN} / \mathrm{m} 2$.After calculations, live load on each R.C frame $=2.25 \mathrm{kN} / \mathrm{m}$.

\subsubsection{Earthquake Load}

The structures are designed for Zone-5 (Jammu and Kashmir), Zone factor taken as 0.36. For all structures, Soil type II, Response Reduction Factor $=5$, Importance Factor $=1$ are considered as per IS 1893-2016 [31].

\section{Analysis Methods}

For the analysis, two cases are considered as shown in Figure.1. Each story is assumed to be 3 meters high. In this study, elastic linear analysis and non-linear load-controlled pushdown analysis was carried out to understand the behavior of two-dimensional low rise reinforced concrete framed structures by evaluating demand capacity ratios at critical structural elements and visualizing the hinge formation pattern, Displacement of joints adjacent to removed column and at top story along $\mathrm{x}$-axis and $\mathrm{z}$-axis are also evaluated. The step-by-step load multiplication was applied as per GSA guidelines through the Envelope Loading combination [32] and GSA loading combination [24], to safeguard a more truthful likelihood of the dynamic effect. To evaluate the Behavior of two-dimensional low rise reinforced framed structures subjected to progressive collapse using linear and Non-Linear static analysis with and without the U.S. General Services Administration, GSA Guidelines [25], two-column removal positions are only considered as shown in Figure.2a.

Case 1- Missing of Corner Column.

Case 2- Missing of Middle Column.

\subsection{Loading Criteria}

When executing elastic analysis, the below-mentioned vertical load combinations are directed in a downward direction if the column is removed statically, the gravity load increases as per G.S.A Guidelines [25]. To get progressive-collapse behavior, the Load arrangement for the factored region (affected region above missing column) is given by Eq. (1), and the unfactored region (remaining regions) is given by Eq. (2). When the analysis is done without using GSA guidelines load combinations used are as shown in Figure.2b

Above the Missing column Region/position.

Factored Region/Area Load = 2 (D. L+0.25L.L)

Adjacent to the Missing column Region/position

Unfactored Region/ Area Load= Envelope Load Combination IS 875-1987 (Part 1,2 and 5)

\subsection{Analysis Loading Combinations}

\subsubsection{Envelope Loading}

This type of loading comprises the envelope of Fourteen loading combinations which are as following: -

(1) 1.5 D.L

(2) 1.5 D. L+1.5 L.L

(3) 1.2 D. L+1.2 L. L+1.2 E.Q(x)

(4) 1.2 D. L+1.2 L.L-1.2 E.Q(x)

(5) 1.2 D. L+1.2 L. L+1.2 E.Q(y)

(6) 1.2 D. L+1.2 L.L-1.2 E.Q(y)

(7) 1.5 D. L+1.5 E.Q(x)

(8) 1.5 D. L-1.5 E.Q(x)

(9) 1.5 D. L+1.5 E.Q(y)

(10) 1.5 D. L-1.5 E.Q(y)

(11) 0.9 D. L+1.5 E.Q(x)

(12) 0.9 D. L-1.5 E.Q(x)

(13) 0.9 D. L+1.5 E.Q(y)

(14) 0.9 D. L-1.5 E.Q(y)

Where

D.L= Dead Load

L.L= Live Load

$\mathrm{E} \cdot \mathrm{Q}(\mathrm{x})=$ Earthquake load along $\mathrm{x}$-direction and

E.Q(y)=Earthquake load along y-direction respectively 


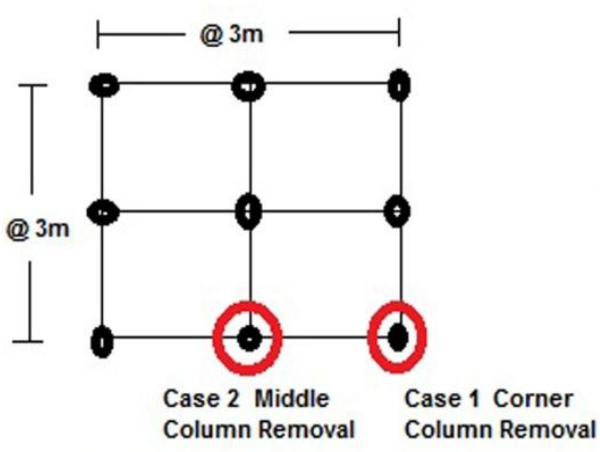

(a) Plan-View of Case A

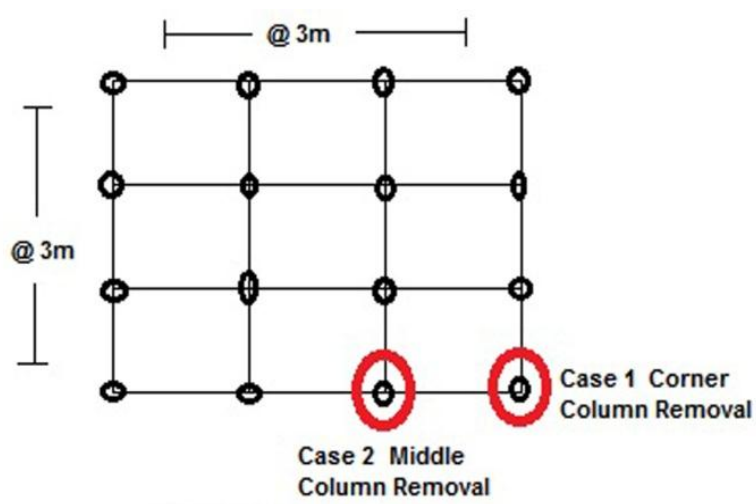

(b) Plan-View of Case C

Figure 2a. Location of Column Removal member

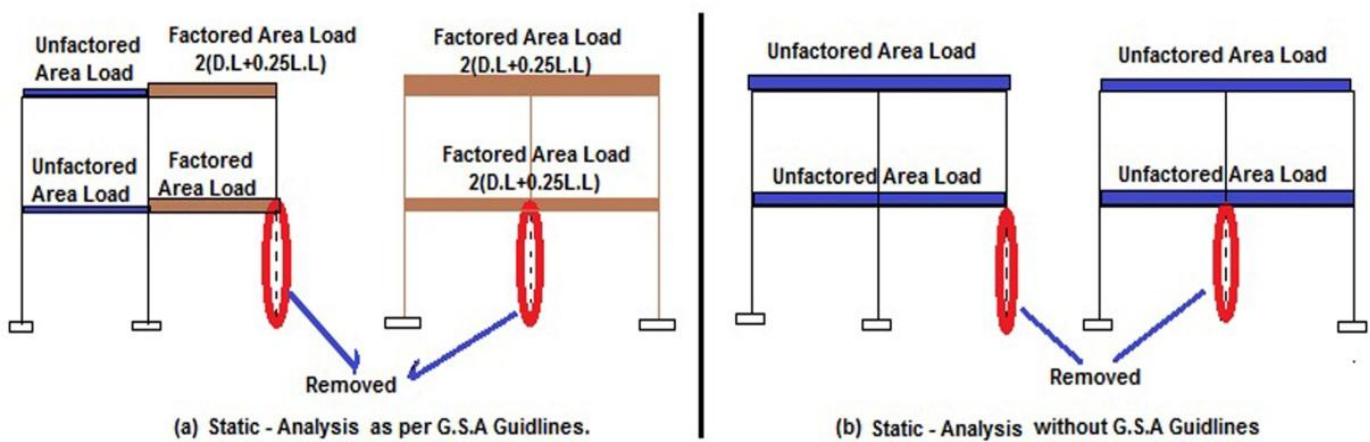

Figure 2b. Load Combinations and locations for different column removal scenarios.

\subsubsection{GSA Loading}

According to the U.S. GSA (2003) Guidelines [25] General Services Administration, the possibility of progressive collapse is evaluated when a column located at first story of a building structure is eliminated from one of four zones:

(1) Elimination of an exterior column in the intermediate of the short side,

(2) Elimination of an exterior column in the intermediate of the long side,

(3) Elimination of a corner column, and

(4) Elimination of an interior column.

Only the first three cases are taken into account in this article.

The corresponding load arrangement is directed in downward direction to the building structure when conducting elastic analysis:

Load $=2$ (D.L +0.25 L.L)

This load arrangement directed in gravitational direction is known as the GSA loading combination.

Where

D.L is Dead load and

L.L is Live load.

\section{Progressive Collapse Analysis, Results and Discussions}

\subsection{Linear Static Analysis}

GSA (2003) guidelines [25] suggest a general loading factor for static analysis. Equation (1) indicates the load scenario.

The Demand Capacity Ratio (DCR) is used to assess the acceptance criterion for the primary and secondary structural components, as shown in equation (3).

Demand Resistance Ratio (DCR) $=$ QUD / QCE

Where, QUD = Demand calculated from linear elastic analysis in element or beam-column joints (moment, shear, axial force, and combined forces).

QCE = Un-factored resistance of the element and/or connection/joint (moment, shear, axial force, and combined forces).

GSA specifies the following permissible Demand resistance ratio values:

DCR values that are higher than the permissible limits are regarded as abnormal or damaged.

- Demand resistance ratio $<2.0$ for standard or regular building configurations 
- Demand resistance ratio $<1.5$ for unusual or irregular building configurations

GSA guidelines [24] allow increasing the asset or strength of the design material by strength-increasing factors in calculating the competences of the elements/components or connections to detect the estimated material strengths. As per GSA guidelines, the strength-increase factors to be used for both concrete and reinforcing steel are 1.25 . To evaluate the behavior for progressive collapse of $2 \mathrm{D}$ Low rise RCC framed structures using linear static analysis, Figure.3a and Figure.4a, Figure.3b, and Figure.4b show the demand capacity ratio(flexure) for the Envelope Loading combination and G.S.A Loading Combination for two-column removal Cases.
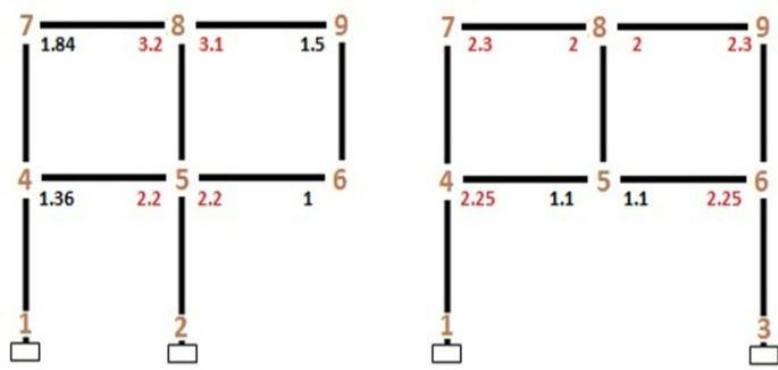

D/C Ratio (E.L.C)

Figure 3a. Demand capacity ratio for Case A (2 Bay 2Story), without considering Dynamic Increase factor for removal of corner column and middle column.

After column deletion, the demand capacity ratio is established in the context of demand as a member strength in respect of the loading combinations as mentioned in Equation 1 and Equation 2. Capacity is calculated for the designed reinforcement of that section. In all these cases, it can be observed that the adjacent joints are very much affected due to column removal as the given load gets transferred by the alternate load path method as shown in red color. Also, the top story is most vulnerable to enhance progressive collapse due to the large demand capacity ratio for flexure compared to the bottom story.
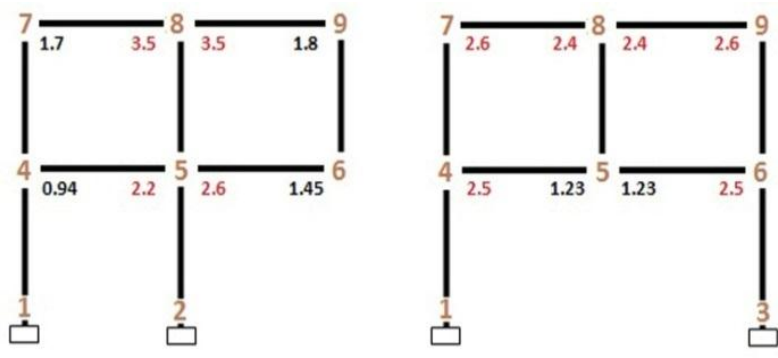

D/C Ratio (GSA)

Figure 3b. Demand capacity ratio for Case A (2 Bay 2Story), Considering Dynamic Increase factor for removal of corner column and middle column

When the corner column is removed statically, the demand capacity ratio at column removal location is less than 2 irrespective of loading combination but the demand capacity ratio at adjacent joints exceeds valve 2 and couldn't pass while performing design and analysis as shown in Figure 3a and Figure 3b. As the number of stories increases from two to three, the demand capacity ratio at top story joints is more compared to bottom story joints which indicate, top story structural elements are under severe stress due to loss of vertical member at the ground story which shows load resisted by removed column before removal is directly proportional to load transferred by top story beam elements as shown in Figure 4a and Figure 4b.

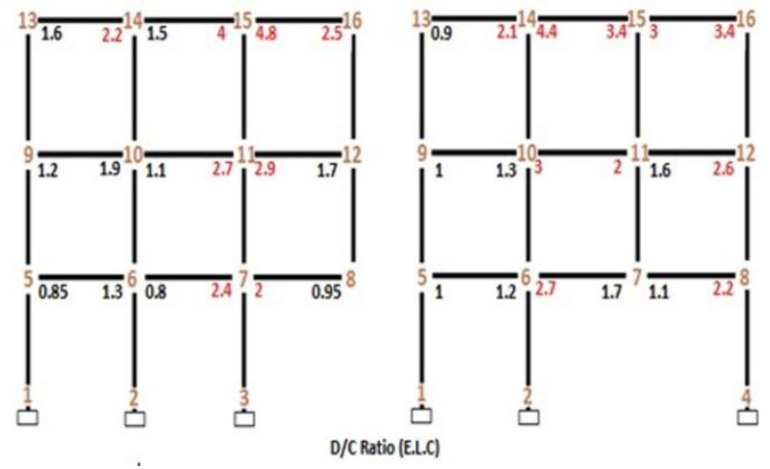

Figure 4a. Demand capacity ratio for Case C (3 Bay 3Story), without considering Dynamic Increase factor for removal of corner column and middle column.

When the middle column is removed statically, the demand capacity ratio at or just above column removal location shows no failure except at top story beam elements. But at the adjacent beam-column joints either the left side or right side of the column removal location, the demand capacity exceeds valve 2 irrespective of the type of loading combination as shown in Figure $3 \mathrm{a}$ and Figure $3 \mathrm{~b}$. As the number of stories increases, the demand capacity ratio also increases with the maximum at top beam-column joints and minimum at bottom beam-column joints as shown in Figure $4 \mathrm{a}$ and Figure $4 \mathrm{~b}$

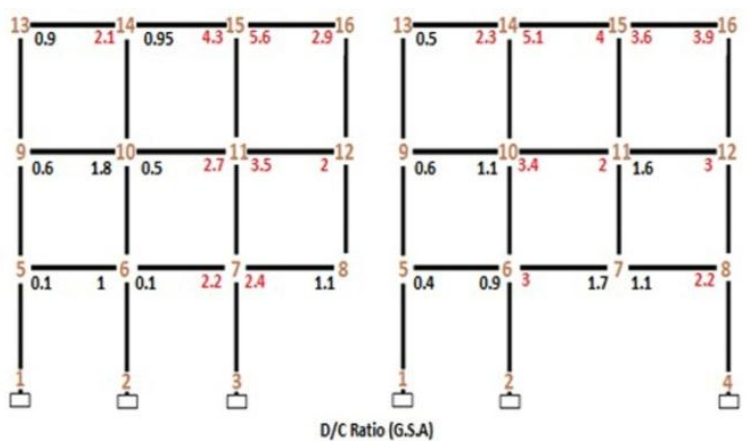

Figure 4b. Demand capacity ratio for Case C (3 Bay 3Story), Considering Dynamic Increase factor for removal of corner column and middle column.

When Column is removed statically at the corner or 
middle location of the longer side of the building plan, the demand capacity ratio is observed maximum towards the interior side where there is more possibility of gaining alternate load path from having a greater number of beam-column joints compared to those joints which are located at the extreme side of the building as shown in Figure $4 \mathrm{a}$ and Figure $4 \mathrm{~b}$. When the analysis was done for the Envelope loading combination in which no particular dynamic increase factor is considered and GSA loading combination where dynamic increase factor of 2 is considered, it was concluded that the behavior of $2 \mathrm{D}$ reinforced concrete framed structure designed seismically is almost the same for both type of loadings, which indicates those structures which are designed seismically possess inherent property to resist progressive collapse to some extent as GSA loading is meant for determining the potential of structure to progressive collapse.

\subsection{Non-Linear Static Analysis}

In this study, non-linear static analyses are carried out through the allocation of auto hinge properties to framework elements. The Finite Element Program automatically designs for each hinge a generated hinge property. Axial, Torsion, Moment, Shear, and coupled are the five default hinge options. Hinge properties are assigned using the cross-section and reinforcement information given by the user. In this case default moment hinges, are used from SAP2000 V.20

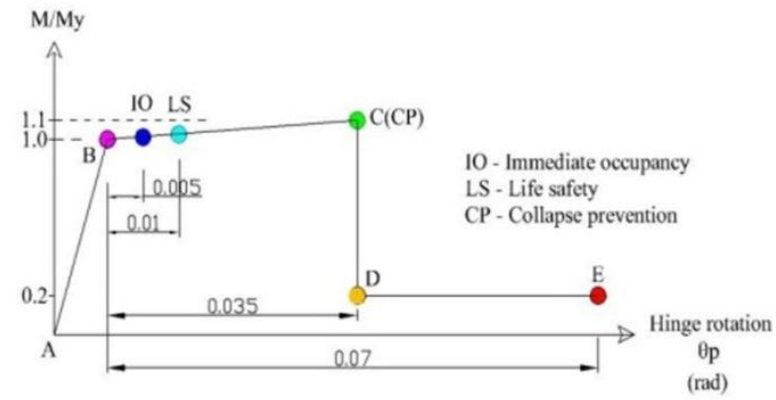

Figure 5. Plastic Hinge

The autonomous M3 hinge feature from ASCE 41-13 [29] has been added to the beam components by choosing them and selecting it from the specified option. According to the early study, the flexural failure mode of beam elements dominates the collapse of reinforced concrete buildings under column-removal conditions, hence only this failure mechanism, rather than shear or prospective column failure, is addressed. For non-linear static analysis, the plastic hinge model, as shown in Figure5, is applied to beam ends. Tables in ASCE 41-13 are used, along with item I of Table 10-7 (concrete beams-flexure) [29],[30]. In SAP2000 V.20, the behavior and response of a building are observed for the moment rotation relationship. Until the hinge yields at point $\mathrm{B}$, there is no plastic deformation. Following that, there's a point $\mathrm{C}$, which represents the hinge's full potential. The hinge's force capacity diminishes after point $\mathrm{C}$, reaching point $\mathrm{D}$, which corresponds to the hinge's latent power.
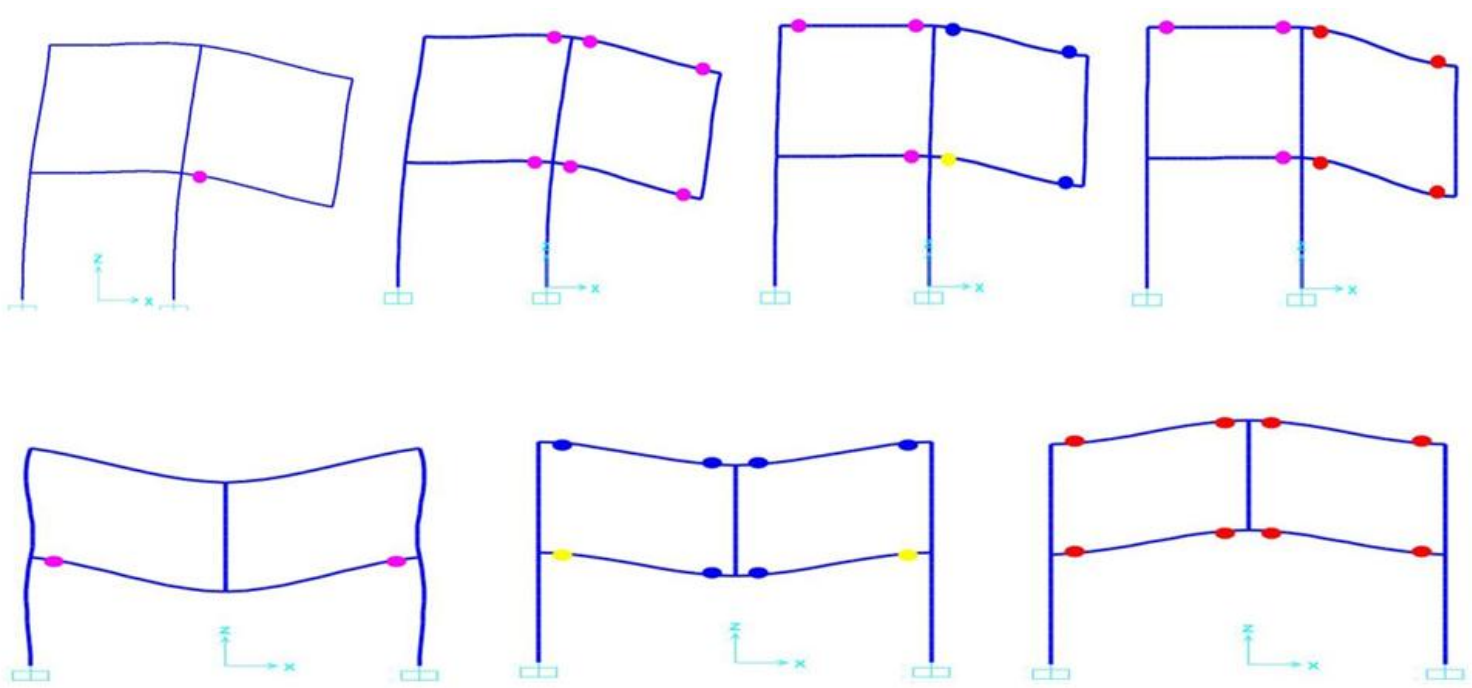

(a) Envelope loading Combination 

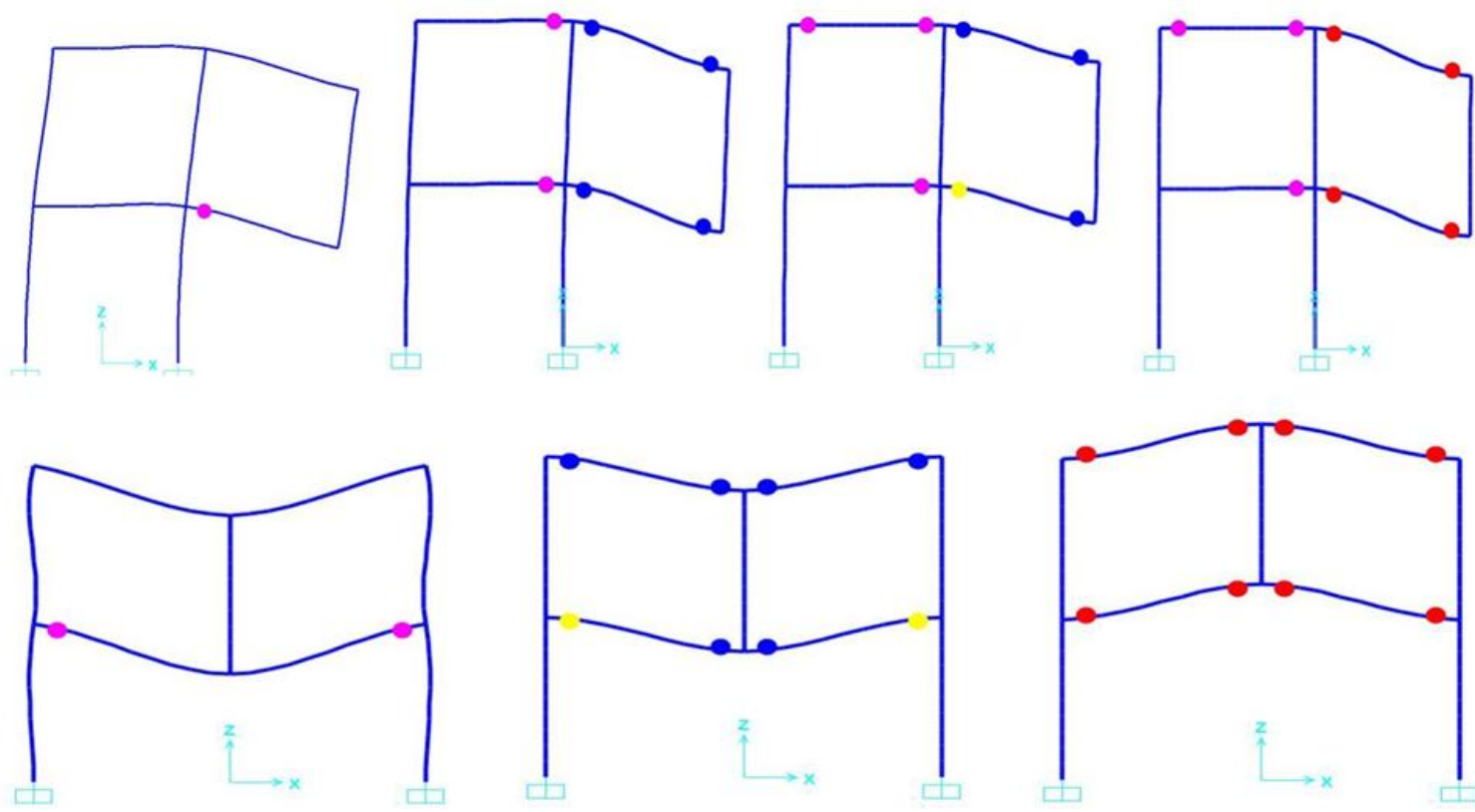

(b) GSA Loading Combination

Figure 6. Hinge formation pattern for Case A ( 2 bay 2story), Removal of corner column and middle column.

Point $\mathrm{E}$ denotes the hinge's ultimate displacement power, after which the hinge will fail. The moment hinges properties were determined using the ASCE 41-13 seismic design code and adapted for progressive collapse analysis to envelope and GSA loading combinations. "The maximum permissible rotation in a plastic hinge is increased from 0.02 rad to $0.035 \mathrm{rad}$, which correlates to the collapse prevention efficiency level on the Moment vs Rotation curve. The GSA Guidelines for RC frames suggest this, to account for strain hardening, the slope from point B to $\mathrm{C}$ is taken to be $10 \%$ of the elastic slope. The residual strength ratio of 0.2 corresponds to point D. Since the GSA Guidelines don't define a valve for point $\mathrm{E}$ as a failure limit, a valve of $0.07 \mathrm{rad}$. is used as an average of the DoD, U.S. Department of Defence Guideline" [27] valves. The compressive strength and tensile yield strength of concrete for reinforced steel were also increased by a factor of 1.25. (GSA 2003) [25].
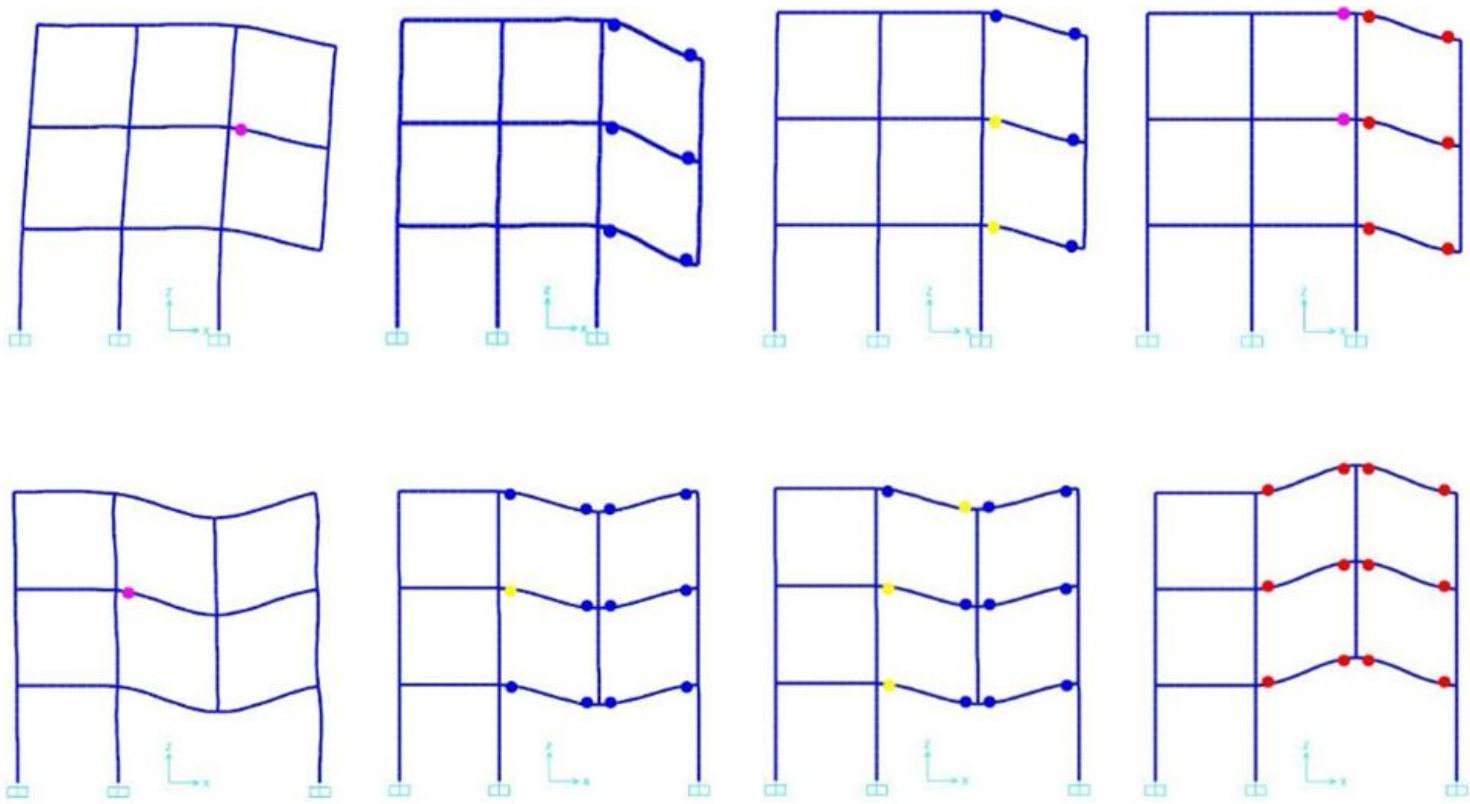

(a) Envelope loading Combination 

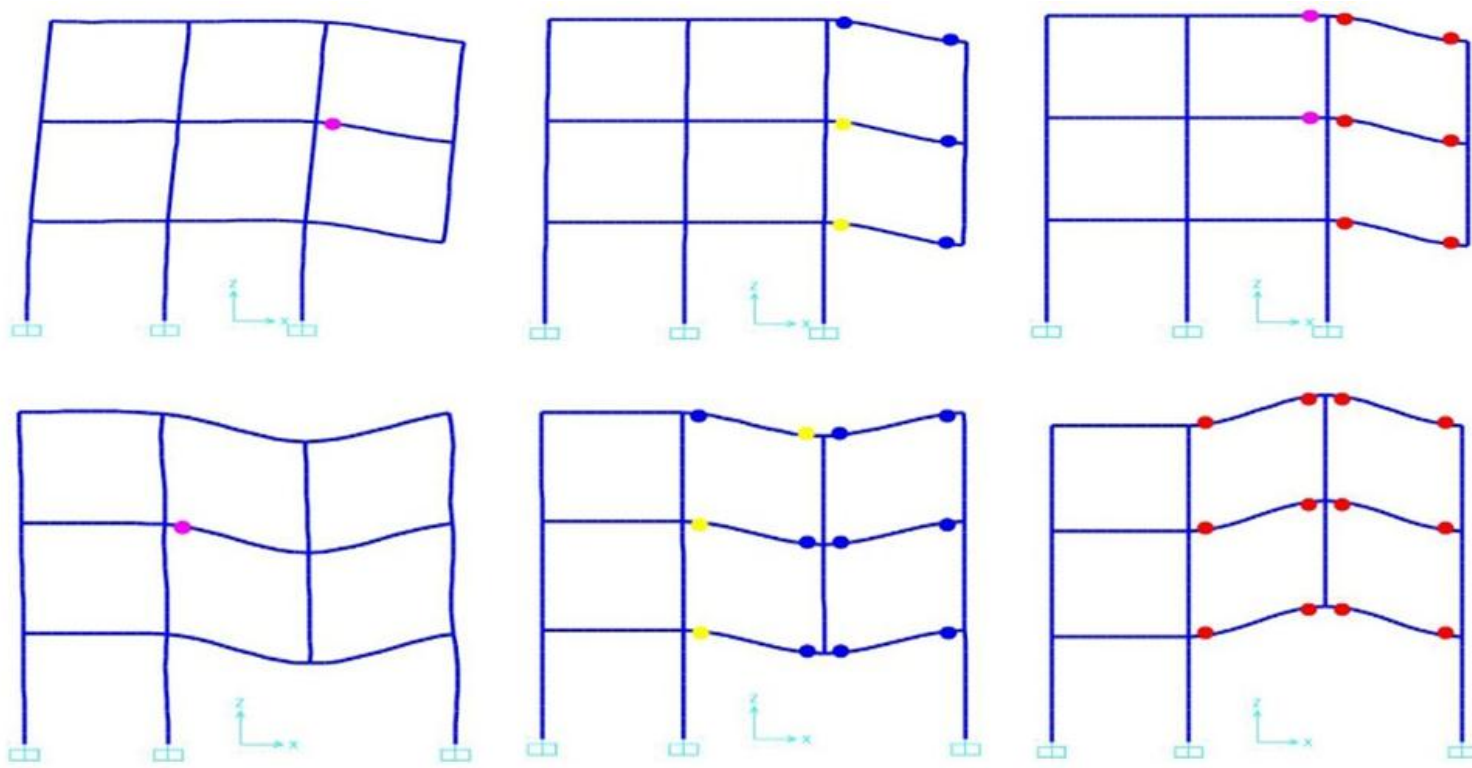

(b) GSA Loading Combination

Figure 7. Hinge formation pattern for Case C ( 3 bay 3story), Removal of corner column and middle column.

The hinge formation pattern obtained for $2 \mathrm{D}$ low rise RCC framed models for different types of loading combinations is shown in Figure 6 and Figure 7 for Case $\mathrm{A}$ and Case $\mathrm{C}$ respectively. It can be observed that the hinges are formed at all those points or spots where the demand capacity ratio surpasses valve 2 . Therefore, the hinge formation pattern is in good agreement with Linear static analysis results. Also, the hinge formation behavior is almost similar for both types of loading combinations irrespective of column removal locations. The only difference lies in the number of steps for obtaining pushdown results. GSA loading combination takes lesser steps compared to Envelope loading combination but the Ultimate results are almost similar.

\subsection{Displacement of Joints along $\mathrm{X}$-axis and $\mathrm{Z}$-axis}

The displacement of the beam-column joints above the column removal location and adjacent to the removed column locations along $\mathrm{x}$-direction and $\mathrm{z}$-direction are also investigated for both Cases A and C. As shown in
Figure 8 and Figure 9. red colour arrow with having prefix indicates displacement along $\mathrm{x}$-direction with magnitude represented by its prefix in numbering order, on the other hand, green colour arrow shows displacement along z-direction with prefix meant for providing a measure of the magnitude of displacement. The following conclusions were made.

When the corner column was removed statically, the displacement along $\mathrm{x}$-direction of beam-column joints at the top story is maximum, followed by the bottom story beam-column joints and minimum at just above the column removal location. Whereas the displacement along z-direction is maximum at just above column removed joint followed by the top story beam-column joint and minimum at beam-column joint adjacent to removed column location as shown in Figure 8 , But the displacement along the $\mathrm{x}$-direction and $\mathrm{z}$-direction for both types of loading combinations are almost same as can be seen from Table 1, Table 2, Table 3 and Table 4 respectively. 

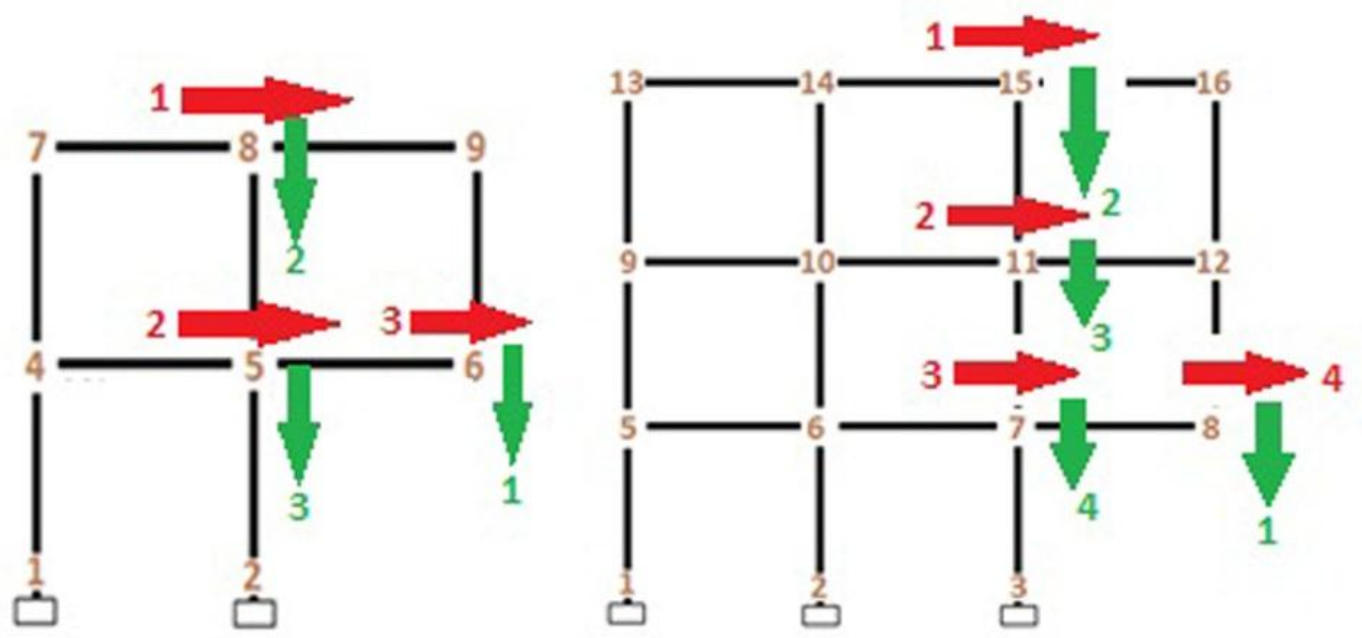

Figure 8. Displacement of Joints along X-axis (red arrow) and Z-axis (green arrow) for Case A (2 Bay 2Story) and Case C (3 Bay 3Story), Removal of corner column.

Table 1. When Corner Column is Removed CASE A

\begin{tabular}{|c|c|c|c|}
\hline Displacement along $\mathbf{x}$-axis(meters) & JOINT5 & JOINT6 & JOINT8 \\
\hline ELC $^{\text {\% }}$ & 0.00268 & 0.00266 & 0.01044 \\
\hline GSA $^{\text {\% }}$ & 0.00269 & 0.00267 & 0.01043 \\
\hline
\end{tabular}

*Envelope loading Combination.

$\%$ GSA Loading Combination.

Table 2. When Corner Column is Removed CASE A

\begin{tabular}{|c|c|c|c|}
\hline Displacement along z-axis(meters) & JOINT5 & JOINT6 & JOINT8 \\
\hline ELC $^{*}$ & $-1.70 \mathrm{E}-04$ & -0.06856 & $-2.45 \mathrm{E}-04$ \\
\hline GSA $^{\text {\% }}$ & $-1.70 \mathrm{E}-04$ & -0.06852 & $-2.43 \mathrm{E}-04$ \\
\hline
\end{tabular}

Table 3. When Corner Column is Removed CASE C

\begin{tabular}{|c|c|c|c|c|}
\hline Displacement along x-axis(meters) & JOINT7 & JOINT8 & JOINT11 & JOINT15 \\
\hline ELC $^{\text {* }}$ & 0.00106 & 0.00104 & 0.00436 & 0.00794 \\
\hline GSA $^{\text {\% }}$ & 0.00106 & 0.00104 & 0.00436 & 0.00795 \\
\hline
\end{tabular}

Table 4. When Corner Column is Removed CASE C

\begin{tabular}{|c|c|c|c|c|}
\hline Displacement along z-axis(meters) & JOINT7 & JOINT8 & JOINT11 & JOINT15 \\
\hline ELC $^{\text {* }}$ & $-2.30 \mathrm{E}-04$ & -0.06676 & $-3.79 \mathrm{E}-04$ & $-4.43 \mathrm{E}-04$ \\
\hline GSA $^{\text {\% }}$ & $-2.29 \mathrm{E}-04$ & -0.06675 & $-3.77 \mathrm{E}-04$ & $-4.39 \mathrm{E}-04$ \\
\hline
\end{tabular}
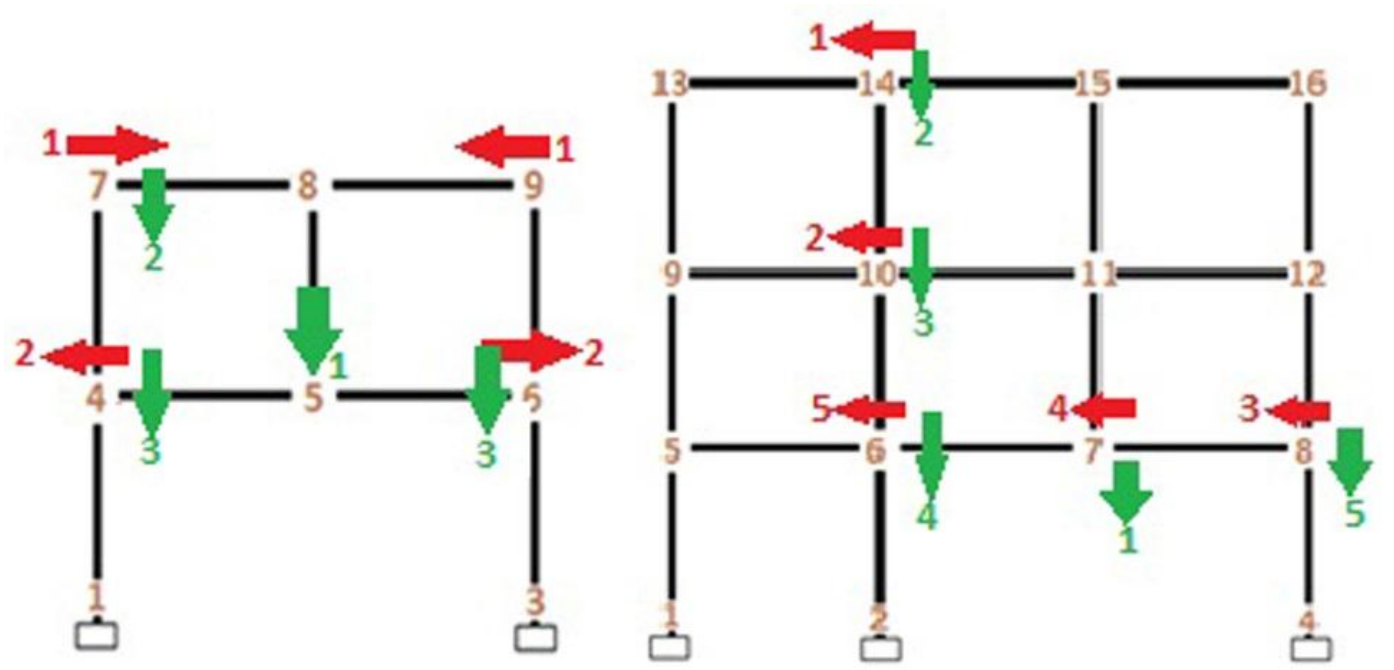

Figure 9. Displacement of Joints along X-axis (red color arrow) and Z-axis (green arrow) for Case A (2 Bay 2Story) and Case C (3 Bay 3Story), Removal of middle column. 
Table 1a. When Middle Column is Removed CASE A

\begin{tabular}{|c|c|c|c|c|}
\hline Displacement along x-axis(meters) & JOINT4 & JOINT5 & JOINT6 \\
\hline ELC $^{*}$ & $-1.69 \mathrm{E}-05$ & 0 & $1.69 \mathrm{E}-05$ & $2.38 \mathrm{E}-05$ \\
\hline GSA $^{\%}$ & $-1.67 \mathrm{E}-05$ & 0 & $1.67 \mathrm{E}-05$ & $2.37 \mathrm{E}-05$ \\
\hline
\end{tabular}

Table 2a. When Middle Column is Removed CASE A

\begin{tabular}{|c|c|c|c|c|}
\hline Displacement along $\mathrm{z}$-axis(meters) & JOINT4 & JOINT5 & JOINT6 & JOINT7 \\
\hline ELC $^{*}$ & $-9.35 \mathrm{E}-05$ & -0.0639 & $-9.35 \mathrm{E}-05$ & $-1.33 \mathrm{E}-04$ \\
\hline GSA $^{\%}$ & $-9.43 \mathrm{E}-05$ & -0.0639 & $-9.43 \mathrm{E}-05$ & $-1.34 \mathrm{E}-04$ \\
\hline
\end{tabular}

Table 3a. When Middle Column is Removed CASE C

\begin{tabular}{|c|c|c|c|c|c|}
\hline $\begin{array}{c}\text { Displacement along } \\
\text { X-axis(meters) }\end{array}$ & JOINT6 & JOINT7 & JOINT8 & JOINT10 \\
\hline ELC $^{*}$ & $-5.33 \mathrm{E}-04$ & $-5.28 \mathrm{E}-04$ & $-5.23 \mathrm{E}-04$ & -0.00156 & -0.00302 \\
\hline $\mathbf{G S A}^{\%}$ & $-5.34 \mathrm{E}-04$ & $-5.29 \mathrm{E}-04$ & $-5.24 \mathrm{E}-04$ & -0.00156 & -0.00301 \\
\hline
\end{tabular}

Table 4a. When Middle Column is Removed CASE C

\begin{tabular}{|c|c|c|c|c|}
\hline $\begin{array}{c}\text { Displacement along } \\
\text { Z-axis(meters) }\end{array}$ & JOINT6 & JOINT7 & JOINT8 & JOINT10 \\
\hline ELC & $-2.03 \mathrm{E}-04$ & -0.06441 & $-1.40 \mathrm{E}-04$ & $-3.31 \mathrm{E}-04$ \\
\hline GSA $^{*}$ & $-2.03 \mathrm{E}-04$ & -0.06436 & $-1.41 \mathrm{E}-04$ & $-3.30 \mathrm{E}-04$ \\
\hline
\end{tabular}

When the middle column was removed, displacement of joints above or at column removal location along the $\mathrm{x}$-direction is zero or negligible. But the adjacent beam-column joints displaces either in positive $\mathrm{x}$-direction or in negative $\mathrm{x}$-direction depending on the position of the beam-column joint to column removal location. In case the column is removed at the exact middle as in Figure.9, the top story left-sided beam-column joints displace maximum along positive $\mathrm{x}$-direction whereas the top story right-sided joint to column removal location displaces with the same maximum magnitude but along negative $\mathrm{x}$-direction. The beam-column joints adjacent to column removal location at bottom story displaces in opposite direction, left-sided joint along negative $\mathrm{x}$-direction and right-sided joint to column removed location along positive $\mathrm{x}$-direction with minimum magnitude compared to top story joints. This is very well in agreement with experimental data given by authors S, Yu, J. and Tan, K.H. [14], Sasani, M., and Sagiroglu [15] and Choi H, Kim, J. [17]

In case the column is removed at the center of the longer span of the building plan as per Figure.9, the top story joints, as well as bottom story joints, displaces along negative $\mathrm{x}$-direction that is towards the building structure with maximum displacement valve at the top story and minimum at the bottom story as shown in Table $3 \mathrm{a}$ and Table 4a. on the other hand, Displacement along $\mathrm{z}$-direction for middle column removal case is maximum just above the column removal location in push downward direction, followed by top story beam-column joints and ultimately minimum magnitude at bottom story joints which are adjacent to column removed location as shown in Figure. 9 by green color arrows with prefix numbering from 1 to 5 .

After analysis for displacement along the x-direction and $\mathrm{z}$-direction, it was concluded that the behavior is almost similar for both types of loading combinations for both types of column removal cases. This analysis also boosts the inherent property of resisting progressive collapse by seismically designed 2D low rise reinforced concrete framed structures. It also clarifies the underestimation of the Dynamic increase factor for seismically designed low rise models to resist progressive collapse by acquiring similar types of results in terms of beam-column joint displacements while considering dynamic increase factor and without considering dynamic increase factor in the above-mentioned case study.

\section{Correlation between Linear and Nonlinear Static Results}

Comparison of linear static and nonlinear static analysis findings for two types of load combinations, one that does not follow GSA recommendations and the other that does, reveals that hinge formation occurs only at those locations where the demand capacity ratio in flexural surpasses acceptance criteria of GSA Guidelines. Hence, in locations where the demand capacity ratio exceeds the permissible valves in the linear static analysis, there is a high possibility that the member components exceeded their elastic limits during the column failure scenario. Following the failure of a particular column due to 
anomalous loading, appropriate reinforcement to restrict the DCR within the acceptability requirements, as well as suitable detailing, can be used to avoid progressive collapse incompetence of beams and columns.

Secondly, demand capacity ratios are almost similar for both types of load combinations which are validated by nonlinear static analysis results by revealing a similar pattern of hinge formation. Hence, when a low-rise RCC structure is seismically designed and analyzed statically, the behavior of the structure is assessed from demand capacity ratios, hinge formation patterns and displacement of beam-column joints at a critical location along the $\mathrm{x}$-axis and $\mathrm{z}$-axis respectively are almost similar for both cases. Where in one case (E.L.C case) dynamic increase factor (DIF) of 2 multiplied to load combination as the dynamic effect is not considered, and in the second case (G.S.A case) the dynamic increase factor of 2 multiplied to load combination is considered. Thus, upgraded seismic detailing can knowingly improve comprehensive behavior in counterattacking progressive collapse, these structures possess the intrinsic property for counterattacking progressive collapse. So, no need to design these structures for anomalous loads like accidental loads. Or in other words the dynamic increase factor of 2 endorsed by GSA guidelines (can be underestimated when GSA recommendation for progressive collapse potential procedure is considered where collapse potential is decided from the valve of $200 \%$ for demand resistance ratio taking into account the dynamic effect and overestimated when general load carrying capacity of seismically designed low rise RCC structure is considered, as these structures can easily resist these anomalous loads without designing for progressive collapse potential, Marchiş A.G. Ioani AM, Cucu HL,Mircea C.[13],[22] recognized final loading capacity of models considered for restrained seismic region and high seismic loading as $128 \%$ and $177 \%$ of the GSA Loading. In our study, rather than getting a different type of results, a similar type of behaviors is observed, these findings are true and can be verified from Marchiş A.G. Ioani AM, Cucu HL,Mircea C.[13],[22].

\section{Conclusions}

In this study, the behavior of 2D low-rise reinforced concrete framed structures to progressive collapse designed for the high seismic region as per Indian standard code was investigated. Linear static analysis was conducted with two types of loading combinations first to establish progressive collapse behavior of structural models through demand capacity ratio. Nonlinear static analysis was conducted to validate these results. In addition, the impact of seismic design on progressive collapse-resistance was explored, which can be summarized as: -
(1) By using linear static analysis, it was observed from demand capacity ratio that in the case of $2 \mathrm{D}$ low-rise seismically designed models, for corner or middle column removal scenarios upper story or top story beam-column joints are more critical than lower or bottom story beam-column joints.

(2) By using non-linear static analysis, the hinge formation pattern observed indicates that the hinges have gone beyond E-state(failure) at all those locations where the demand capacity ratio exceeds valve 2 , which is well in agreement with linear static analysis results, the hinge formation behavior for envelope loading combination and GSA loading combination are almost similar, the only difference lies in the number of pushdown steps to obtain results. GSA loading combination takes a smaller number of pushdown steps to obtain the same results compared to the Envelope loading combination.

(3) The simplest linear and nonlinear static analysis shows that when the column is removed statically without considering the dynamic increase factor which in this case is written as Envelope loading combination and when the column is removed dynamically, the same static analysis with loading multiplied by factor 2 to account for dynamic nature of loading which in this case is written as GSA loading combination, the results are almost similar for both types of loading combinations as observed from demand capacity ratio, hinge formation pattern and displacement of beam-column joints along $\mathrm{x}$-direction and $\mathrm{z}$-direction, As a result, for 2D low-rise reinforced concrete framed seismically built structures, the dynamic increase factor proposed by GSA (2003) recommendations to be employed in non-linear static analysis to approximate a dynamic solution is underestimated.

(4) Thus, improved seismic detailing or improved seismically designed low-rise reinforced concrete framed structures can significantly improve global behavior in resisting progressive collapse due to the loss of any vertical structural element. These structures possess the inherent property for resisting progressive collapse.

\section{REFERENCES}

[1] Karimiyan, Somayyeh (2020), "Comparison of seismic progressive collapse distribution in low and midrise RC buildings due to corner and edge columns removal".

[2] Ghaemian,Saeed, Muderrrisoglu, Ziya, Yazgan, Ufuk (2020), "The effect of finite element modelling assumptions on collapse capacity of an RC frame building". Earthquakes and Structures,18(5),555-565.http://dx.doi.org/10.12989/ea s.2020.18.5.555 
[3] Kulkarni,Anadee M, Dattaa, Debarati (2019), "Probabilistic analysis of RC beams according to IS456:2000 in limit state of collapse". Structural Engineering and Mechanics, 71(2), 165-173. http://dx.doi.org/10.12989/sem.2019.71.2.165

[4] Jalilkhani, Maysam, Manafpour, AliReza (2018), "Evaluation of seismic collapse capacity of regular RC frames using nonlinear procedure". Structural Engineering and Mechanics, 68(6), 647-660. http://dx.doi.org/10.1298 9/sem.2018.68.6.647

[5] Starossek U. Typology of progressive collapse. Eng Struct 2007; 29(9):2302-7

[6] Starossek and M. Haberland, Measures of structural robustness- requirements and applications. In ASCE SEI 2008 Structures Congress - Crossing Borders, Vancouver, Canada, 2008.

[7] E. Brunesi, F. Parisi (2017), "Progressive collapse fragility models of European reinforced concrete framed building based on push down analysis" Engineering structures: 152, 579-596. http://dx.doi.org/10.7712/100016.2155.5285

[8] Khalid M Mosalam, MohamedTalat, Sangjoon Park.(2017), "Modelling progressive collapse in reinforced concrete frame structures" $14^{\text {th }}$ World Conference on Earthquake Engineering.,Beijing., China, October.

[9] Abbasnia, Reza, Foad Mohajeri, Usefi, Nima, Rashidian, Omid, (2016), "A new method for Progressive collapse analysis of RC Frames". Structural Engineering and Mecha nics,60(1), 31-50. http://dx.doi.org/10.12989/sem.2016.60. 1.031

[10] E. Brunesi, R. Nascimbe, F. Parisi, N. Augenti (2015), "Progressive collapse fragility of concrete framed structures through incremental dynamic analysis" Engineering structures, 104, 65-79.

[11] Pham Xuandat, Tan Kanghai, Yu Jun. (2015), “A simplied approach to assess progressive collapse resistance or reinforced concrete structures" Engineering structures:101, 45-57.

[12] Theerthananda M P, P C Srinivasa, G M Naveen, "An Investigation of High-Performance Self Compacting Concrete under Flexural Loading," Civil Engineering and Architecture, Vol. 8, No. 6, pp. 1414 - 1418, 2020. DOI: 10.13189/cea.2020.080624.

[13] Marchiş A.G., Moldovan T.S., Ioani A.M. (2013), The Influence of the Seismic Design on the Progressive Collapse Resistance of Mid-Rise RC Framed Structures. Acta Technica Napocensis: Civil Engng. \& Archit., 56, 2, 222-234

[14] Yu, J. and Tan, K.H. (2013), "Structural behavior of RC beam-column sub-assemblages under a middle column removal scenario", J. Struct. Eng., ASCE, 139(2), 233-250. https://doi.org/10.1061/(ASCE)ST.1943-541X.0000658

[15] Sasani, M., Kazemi, A., Sagiroglu, S. and Forest, S. (2011a), "Progressive collapse resistance of an actual 11-story structure subjected to severe initial damage", J. Struct. Eng., ASCE, 137(9), 893-902. https://doi.org/10.10 61/(ASCE)ST.1943-541X.0000418

[16] U. Starossek Avoiding disproportionate collapse of tall buildings Structural Engineering International, 3:238-245, 2008.

[17] Choi H, Kim, J. Progressive collapse-resisting capacity of RC beam-column sub-assemblage. Magazine of Concrete Research, Vol. 63, No. 4, 2011.

[18] Yeong-Min Kim, "Structural Analysis and Conceptual Seismic Design of Large-span Korean Traditional Timber Structure," Civil Engineering and Architecture, Vol. 8, No. 2, pp. 154 - 165, 2020. DOI: 10.13189/cea.2020.080213.

[19] U. Starossek, "Progressive collapse of structures: nomenclature and procedure, "Structural Engineering International, 16(2):113-117, 2006

[20] Hayes,J; Woodson,S; Pekelnicky,R; Poland,C; Corley,W; Sozen,M, "Can Strengthening for earthquake improve blast and progressive collapse resistant" J. Struct. Eng, 131(8), $1157-1177$

[21] Sasani, M. and Sagiroglu, S. (2008b), "Progressive collapse resistance of Hotel San Diego", J. Struct. Eng., ASCE, 134(3), 474-88.

[22] Ioani AM, Cucu HL, Mircea C. "Seismic design vs. progressive collapse: a reinforced concrete framed structure case study". Proceedings of ISEC-4, Melbourne, Australia, 2007.

[23] U. Starossek and M. Wolff. "Design of collapse-resistant structures". In JCSS and IABSE Workshop on Robustness of Structures, BRE, Garston, Watford, UK, 2005

[24] GSA (2013), Alternate Path Analysis and Design Guidelines for Progressive Collapse Resistance, General Services Administration, Washington DC., USA.

[25] GSA, the U.S. General Services Administration. (2003), Progressive collapse analysis and design guidelines for new federal office buildings and major modernization projects.

[26] SAP2000 (2020), Three-Dimensional Static and Dynamic Finite Element Analysis and Design of Structures, Analysis Reference, Version 20.0.0, Computer and Structures, Inc., Berkeley, CA.

[27] U. S. Department of Defense. (2013), "Design of building to resist progressive collapse" UFC 4-023-03. Washington, DC.

[28] "Plain and reinforced concrete -code of practice. "IS 456-2000 Bureau of Indian Standard, New Delhi, India.

[29] ASCE-41, (2006): Seismic Rehabilitation of Existing Buildings", American Society of Civil Engineers, Reston, VA, USA.

[30] ASCE (2010). Minimum design loads for buildings and other structures (7-10), ASCE, Reston, VA.

[31] IS 1893-2016, Criteria for Earthquake Resistant Design of Structures (General Provisions and Buildings), Bureau of Indian Standards, New Delhi, India.

[32] IS 875- 1987 (Part1, Part2, Part3, Part4 and Part5), Code of practice for Design Loads (other than earthquake) for building structures, Bureau of Indian Standards, New Delhi, India. 